\title{
Infertility - an unfinished reproductive rights agenda in India
}

\author{
MALA RAMANATHAN, SUNU C THOMAS
}

Keywords: Infertility, childlessness, reproductive rights, assisted reproduction, ICPD, public health

Twenty-five years after the International Conference on Population and Development (ICPD) mandate in 1994, India has fallen far short of providing universal access to preventive and treatment services for infertility. This mandate was a call to "prioritize the reproductive health and rights of all people" (1), and reproductive health was defined as

.. a state of complete physical, mental and social well-being and not merely the absence of disease or infirmity, in all matters relating to the reproductive system and to its functions and processes. Reproductive health therefore implies that people are able to have a satisfying and safe sex life and that they have the capability to reproduce and the freedom to decide if, when and how often to do so. (1)

The ICPD definition positioned the right to reproduce as a positive right. States were required to provide for their people to realise this right. This would mean expanding the scope of maternal and child health programmes to include access to a choice of contraceptives, bring in medical abortions to manage contraceptive failure, and address gynaecological morbidity and sexually transmitted infections. In this process, the state has ignored another positive reproductive freedom, the freedom of "having the capability to reproduce". This right calls for provision of a comprehensive sexual and reproductive healthcare package that should have been universally available. Such a package would have encompassed preventative and curative care at all levels, starting from primary care with referrals up to tertiary levels for services that needed additional skills and technology like Assisted Reproductive Technology (ART). This has been ignored because the major concerns for policy makers in India were: slowing down population growth $(2,3)$, and avoiding higher investment needed to provide infertility care $(4,5)$.

Over these past decades, options for infertility treatment have improved, but they continue to require relatively higher quality equipment and skills (6). Efforts at developing low cost means and skills to reach infertility treatment to those in the lower- and middle-income countries (7) have been few and the existing services barely address the tip of the iceberg. A pan India study found that adequate staff, basic infrastructure and diagnostic facilities were available in more than 70 percent of the facilities at the district level, but none of the staff had received any training to manage infertility. These facilities were entirely absent at the primary health centre and community health centre levels that serve as first levels of care (8).

\section{The burden of infertility in India, and treatment options}

In India, indirect estimates of infertility using the Census 2011 data indicate that 4.5 out of 100 currently married women in the age group 15-49 years experience childlessness (9). As estimating infertility including both primary and secondary infertility is difficult, indirect estimates approximate it using childlessness, and that is what this measure represents (9). Women experience the stigma associated with infertility far more than men, facing familial disapproval, risk of abandonment and gender-based violence within marriages in India, being a patriarchal and patrilineal society (10). They are reported to also take on the stigma of male infertility within marriage, as a protection from abandonment $(9,11)$.

The social expectation that a married woman has to procreate within a certain period after marriage puts the "blame" on women when they are unable to get pregnant. These women start embodying the idea that the reproductive impairment is in

Authors: Mala Ramanathan (corresponding author - mala@sctimst.ac.in), Professor, Achutha Menon Centre for Health Science Studies, SCTIMST, Thiruvananthapuram, 695011 Kerala, INDIA; Sunu C Thomas (sunusarathomas@gmail.com), India Health Policy and Systems Research Fellow, Kollam, Kerala 691007 INDIA.

To cite: Ramanathan M, Thomas SC. Infertility - an unfinished reproductive rights agenda in India. Indian J Med Ethics. 2021 Oct-Dec; 6(4) NS: 267-9. DOI: 10.20529/IJME.2021.072.

Peer Reviewers:Vibhuti Patel and an anonymous reviewer.

(c) Indian Journal of Medical Ethics 2021 
their body. The notion of the female body harbouring impairment, even when the male body has the problem, puts a lot of pressure on women to prove that their bodies are not impaired, inducing them to seek repeated treatment, with its accompanying physical and emotional trauma (9).

The demand for infertility treatment using the allopathic system is projected to include 11.06 to 14.25 million currently married women in the age group 20-49 years, in 2021, using data from the District Level Household Survey (DLHS-3) of 2007-08 (12). Infertility treatment includes basic investigations, sophisticated diagnostic tests, medical and surgical management of the condition, and use of high-end technological solutions like ART. Where couples or individuals require basic investigation for infertility, they should be entitled to receive ART treatments if needed, but are limited by accessibility and affordability.

In India a majority of ART services are provided by the private sector, and the facilities, if at all available in the public sector, are only offered in the medical colleges (13). There were 1500 ART centres in the country in 2019, including 350 private physician clinics and 1000 sole practitioner-based clinics. There were only 10 ART clinics in public hospitals (14). The reason for this limited public sector presence could be related to the higher costs involved in provisioning. As the infertility care market also remains largely un-regulated (15), it is inevitable that there will be inequity in access to infertility treatment.

The high costs involved in seeking and obtaining treatment causes men and women to abandon treatment through medical means when their financial resources are exhausted. They then take recourse to alternative, unproven therapies in an effort to demonstrate their commitment to begetting a child that is genetically related to the wife and her husband - ie containing their genetic matter (9). This demonstration of their efforts becomes necessary in a society that privileges child bearing for women, particularly of male children (10), and stigmatises childlessness.

\section{The Government of India's response to the demand for infertility treatment}

In the aftermath of the ICPD mandate, the need for a comprehensive sexual and reproductive health package, that included infertility care, was recognised. The 10th Five-year Plan (2002-2007) made allocations for such services, taking into account the levels from primary care all the way up to tertiary referral services (16).

This allocation was made in 2007, but its possible benefits remain unrealised almost 15 years later. While many of the reproductive health mandates were sought to be achieved, the unmet need of "capability to reproduce" was not addressed through public provisioning in spite of the advocacy initiatives of health and other activists.

On the other hand, there has been a rising need for such services. The development of various diagnostic technologies and ARTs to mitigate infertility, and the lack of public provisioning for these has left the people at the mercy of market forces. The burgeoning private sector caters to this need for infertility services, creating inequities in access, with the government merely playing the role of a regulator.

The absence of a rights framework within the evolving policy for infertility is particularly evident when the regulations regarding ART will only consider heterosexual married couples as commissioning parents ${ }^{1}$ (17). This restrictive regulation on the option to use surrogacy to beget children excludes single men and gay or lesbian couples' rights to be commissioning parents. It does not seem to require the state to provide for all of its people, enabling their "capability to reproduce" through treatment options, in case this capability is impaired for whatever reason.

\section{Responsibility of the state}

Within the reproductive rights agenda, therefore, there is a need to reiterate the state's responsibility to provide infertility services through public provisioning that will bridge the equity gap in the existing services. Along with it, all stakeholders, including policy makers, programme planners, medical professionals, activists for women's health or public health activists need to make a concerted effort to reduce or remove the stigma associated with infertility and care seeking for it. This will enable couples and individuals to make their choices regarding reproduction within the private sphere. The law allows for it and social systems ought to respect these choices people make. It is part of the public health and reproductive rights mandate to work towards fulfilling these rights for all people, regardless of their gender or sexual orientation. We need to bring infertility services back on the agenda.

\section{Acknowledgements}

We are grateful to Sandhya Srinivasan and the reviewers for their inputs on an earlier draft. The errors, if any, are our own.

\footnotetext{
${ }^{1}$ Note: Currently the Bill defines commissioning parents as follows:

"Commissioning couple" means an infertile married couple who approach an assisted reproductive technology clinic or assisted reproductive technology bank for obtaining the services authorised of the said clinic or bank. (17: Sec 2(g))
} 


\section{References}

1. United Nations. Report of the International Conference on Population and Development: Cairo, 5-13 September 1994. New York: United Nations; 1995[cited 2021 Sep 10]. 193 p. Available from: https://www.un.org/development/desa/pd/sites/www.un.org.development.desa.pd/files/ icpd_en.pdf

2. Pennings G. Ethical issues of infertility treatment in developing countries. ESHRE Monographs. 2008 Jul 1;2008(1):15-20.

3. Gipson JD, Bornstein MJ, Hindin MJ. Infertility: a continually neglected component of sexual and reproductive health and rights. Bull World Health Organ. 2020 Jul 1;98(7):505-6.

4. Sallam HN. Infertility in developing countries: funding the project. ESHRE Monographs. 2008 Jul 1;2008(1):97-101.

5. Ombelet W. Is global access to infertility care realistic? The Walking Egg Project. Reprod BioMed Online. 2014 Mar 1;28(3):267-72. Doi: 10.1016/ j.rbmo.2013.11.013.

6. Thoma M, Fledderjohann J, Cox C, Kantum Adageba R. Biological and Social Aspects of Human Infertility: A Global Perspective. In: Oxford Research Encyclopedia of Global Public Health [Internet]. Oxford University Press; 2021 [cited 2021 Sep 11]. Available from: https://oxfordre.com/publichealth/ view/10.1093/acrefore/9780190632366.001.0001/acrefore-9780190632366-e-184

7. Ombelet W. Global access to infertility care in developing countries: a case of human rights, equity and social justice. Facts Views Vis Obgyn. 2011;3(4): 257-66.

8. Chauhan S, Unisa S, Joshi B, Kulkarni R, Singh A, Subramanian T, et al. Capacity assessment of district health system in India on services for prevention and management of infertility. Indian J Community Med. 2018;43(1):19.

9. Thomas SC. From diagnosis to parenthood: Event history analysis of infertility treatment trajectories in Kerala, India. [PhD Thesis].Thiruvananthapuram, Kerala:Sree Chitra Tirunal Institute for Medical Sciences and Technology; 2020.

10. Widge A. Sociocultural attitudes towards infertility and assisted reproduction in India. In: Vayena E, Rowe PJ, Griffin PD, eds. Current practices and controversies in assisted reproduction: Report of a meeting. Geneva:WHO, Department of Reproductive Health; 2003. P.60-74.

11. Nahar P, Richters A. Suffering of childless women in Bangladesh: the intersection of social identities of gender and class. Anthropol Med. 2011 Dec; 18(3):327-38.

12. Unisa S. Infertility and Treatment Seeking in India: Findings from District Level Household Survey. Facts Views Vis Obgyn, Monograph. $2010: 59-65$.

13. Widge A, Cleland J.The public sector's role in infertility management in India. Health Policy Plann. 2009 Mar 1;24(2):108-15.

14. IFFS. International Federation of Fertility Societies' Surveillance (IFFS) 2019: Global Trends in Reproductive Policy and Practice, 8th Edition. Global Reproductive Health. 2019 Mar;4(1):e29-e29. Doi: 10.1097/GRH.0000000000000029.

15. Davis MF, Khosla R. Infertility and Human Rights: A Jurisprudential Survey. Colum J Gender \& L. 2020 Sep 7;40(1):1-45.

16. Planning Commission, Govt of India. Family Welfare. Chap 2.10. In: Tenth Five Year Plan, 2002-2007, Vol II [Internet]. 2002. Available from: https:// niti.gov.in/planningcommission.gov.in/docs/plans/planrel/fiveyr/10th/volume2/v2 ch2 10.pdf

17. Ministry of Health and Family Welfare, Govt of India. The Assisted Reproductive Technology (Regulation) Bill, 2020 [Internet]. 2020 Mar 12 [cited 2021 Sep 10]. Available from: https://rajyasabha.nic.in/rsnew/Committee_site/Committee_File/BillFile/Bill/14/142/97\%20of\%202020_2020_10_11.pdf

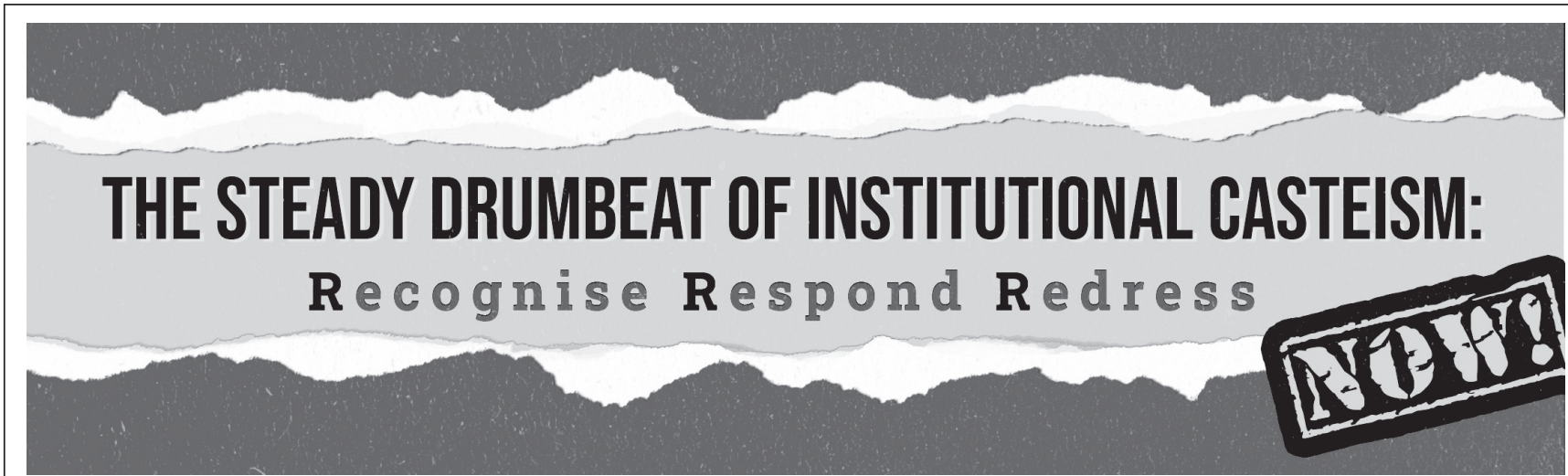

\section{Forum Against Oppression of Women, Forum for Medical Ethics Society, Medico Friend Circle, Peoples' Union of Civil Liberties, Maharashtra}

September 2021

The tragic waste of the death by suicide of Dr Payal Tadvi, resident doctor at the BYL Nair Hospital, Mumbai, on May 22, 2019, stirred the nation's conscience... for a while. That the first woman from the Adivasi Muslim Bhil Community, a scheduled tribe, to pursue a post-graduation in medicine was driven to death in such a manner amounted to "institutional murder".

Since the 1990s, the entry of a visible number of students from marginalised castes has brought overt tensions into university campuses, with constant challenges to the affirmative constitutional policies of reservations in education and employment for the SC and ST communities. Alongside this, growing privatisation in higher education, and attempts to integrate India into the global knowledge economy, have had an impact. This enquiry attempts to study the combined effect of all these trends, specifically in the case of medical education.

The full report can be accessed at: https://fmesinstitute.org/wp-content/uploads/2021/09/The-Steady-Drumbeat-ofInstitutional-Casteism-Recognize-Respond-Redress_Final-report_27Sept21.pdf 